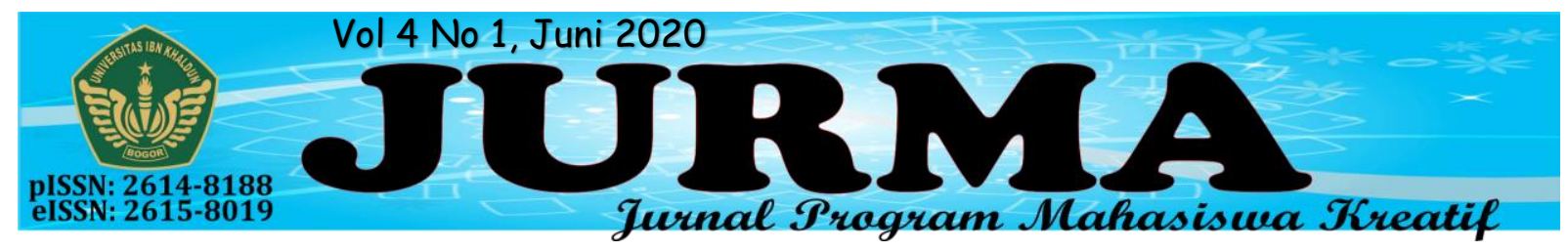

\title{
REDESAIN SATCHEL BAG UKM ZOLA LEATHER UNTUK PARA WANITA YANG MENCINTAI PRODUK DALAM NEGERI
}

\author{
Nurrika Chandra ${ }^{1}$, Bayyinah Nurrul Haq ${ }^{2}$ \\ nurrikachandra@gmail.com ${ }^{1}$ \\ bayyinah.nh@trilogi.ac.id ${ }^{2}$ \\ Program studi Desain Produk, Fakultas Industri Kreatif dan Telematika, Universitas Trilogi.
}

Jl. TMP Kalibata No.4 RT.4/ RW 4, Duren Tiga, Kec. Pancoran, Jakarta Selatan, Daerah Khusus Ibukota Jakarta 12760

\begin{abstract}
ABSTRAK
Inovasi produk berperan besar dalam meningkatkan daya saing UKM. Zola Leather adalah produk hasil UMKM asal Bogor. Ciri khas produk adalah penggunaan bahan kulit sapi asli, tas berukuran kecil - sedang. Target konsumennya adalah perempuan usia $20-35$ tahun Penelitian ini mebahas proses redesain tas yang sudah ada, berdasarkan rekomendasi analisis SWOT, BCG dan Benchmark Wheel. Hasilnya adalah desain tas kulit tipe satchel bag. Tas yang didesain memiliki 2 fungsi dalam 1 produk yaitu dapat digunakan untuk hand bag dan sling bag. Secara tampilan tas ditujukan untuk dipakai untuk acara formal dan non formal.
\end{abstract}

Kata Kunci: Tas Kulit, Satchel Bag, Redesain, Fungsional.

\section{PENDAHULUAN}

\section{Latar Belakang}

Tas merupakan wadah untuk mengumpulkan dan membawa barang lain dalam satu tempat. Pada sisi manfaat, tas pada awalnya hanya digunakan sebagai sarana membawa barang agar lebih mudah. Produk tas yang berada di pasar local persaingnya cukup ketat. Beberapa kota di Indonesia merupakan sentra pengrajin produk berbahan baku kulit seperti Jogjakarta, Bogor dan Bandung.

Tiap kota umumnya memiliki UKM kebanggaan yang sudah memiliki ciri khas dari desain, kualitias dan harga masing masing. Untuk menghadapi persaingan yang makin ketat ini, dibutuhkan penerapan strategi pemasaran yang baik yang tentunya ditunjang oleh inovasi produk yang mampu memenuhi kebutuhan pasar.
Salah satu perusahaan yang bergerak dibidang tas kulit ialah asal Bogor adalah UMKM Zola Leather. Berdiri tahun 2016, sebelum nya Owner Zola Leather yaitu $\mathrm{Bu}$ Mira membuat usaha Sepatu kulit yang berada di pasar anyar, Bogor. Tetapi dengan berjalan nya waktu usaha itu tutup karena menurut nya usaha sepatu terlalu membuat banyak size sehingga banyak produknya yang tidak laku terjual. Akhirnya $\mathrm{Bu}$ Mira dan suaminya mengganti usaha nya menjadi Zola Leather. Sampai saat ini Zola Leather memiliki 20 karyawan dan mempunya toko offline di Jl. Taman Panggelaran Blok D1 No, 7a Lantai 2, Bogor, Jawa Barat.

Produk yang paling diminati yaitu Tas kulit salah satunya ialah Satchel Bag. UKM zola ini juga mempunya beberapa produk series, antar lain Tweely Bag yang 
terdiri dari Satchel bag, Dompet dan pouch. Didorong oleh permintaan pasar yang lebih mengutamakan memiliki manfaat yang banyak maka Pada Redesain kali ini ingin membuat desain yang memiliki beberapa fitur fungsional, yang

\section{TINJAUAN PUSTAKA}

Sejarah awal mula tas mungkin berawal pada jaman prasejarah, dimana tas yang terbuat pada saat itu masih menggunakan kulit dan kayu sebagai bahan dasarnya. Tas yang terbuat dari kulit dipergunakan untuk membawa bahan makanan, sedangkan yang terbuat dari kayu biasanya untuk membawa batu atau kayu potong. Baru pada abad ke-14 bahan yang digunakan untuk membuat tas mengalami pengembangan dari yang sebelumnya kulit dan kayu, menjadi kain, vinyl, dan kulit sintetis. kulit sintetis digunakan untuk membuat tas karena bahan tersebut dapat menjadi alternatif pengganti kulit asli ketika bahan kulit asli sedang habis.

\section{A. Kulit}

Kulit dari ternak besar dan kecil baik sapi, kerbau dan domba serta kambing memiliki struktur jaringan yang kuat dan berisi, sehingga dalam penggunaannya dapat dipakai untuk acara formal ataupun non formal.

Berdasarkan uraian di atas, maka permasalahan yang muncul adalah bagaimana redesain tas untuk Zola Laeather yang sesuai dengan startegi pemasarannya.

dapat dipakai pangan dan non pangan. (Sudarminto, 2000).

\section{B. Teknik Analisis Data}

\section{Analisa SWOT}

Analisis SWOT metode perencanaan strategis yang digunakan untuk evaluasi bagaimana kekuatan (strengths) mampu mengambil keuntungan (advantage) dari peluang (opportunities) yang ada, bagaimana cara mengatasi kelemahan (weaknesses) yang mencegah keuntungan dari peluang (opportunities) yang ada, selanjutnya bagaimana kekuatan (strengths) mampu menghadapi ancaman (threats) yang ada, dan terakhir adalah bagimana cara mengatasi kelemahan menjadi nyata atau menciptakan sebuah ancaman baru.

\section{Matriks BCG}

Kategori-kategori Bintang (Star), Sapi Perah (Cash Cows), Anjing (Dogs) dan Tanda Tanya (Question Marks). 


\section{METODE PENELITIAN}

Pendekatan penelitian yang digunakan adalah Kualitatif dengan jenis perancangan. Penelitian perancangan dilaksanakan dengan bagan alur di bawah ini :

\section{Alur Perancangan}

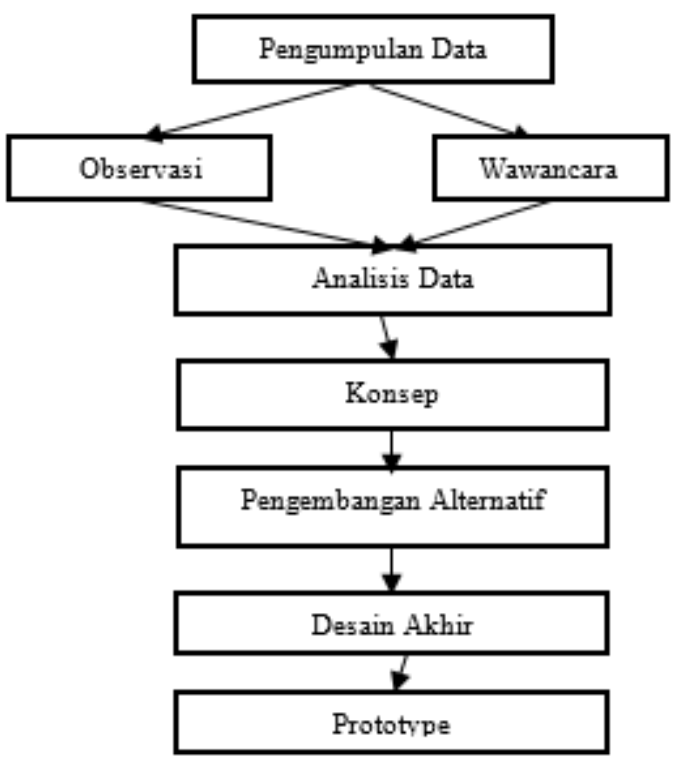

\section{Teknik Pengumpulan Data}

Beberapa cara yang digunakan dalam pengumpulan data yaitu :

Data primer berupa pengumpulan data secara langsung di lapangan dengan cara

\section{HASIL DAN PEMBAHASAN}

\section{Data dan Analisis Data}

\section{a. Profil UKM Zola Leather}

Nama Owner : Mira Nur Gandaniati

Showroom : Jl. Taman Pagelaran Blok D1 No. 7a Lantai 2, Bogor, Jawa Barat.

Ciri Khas : Produk dengan bahan baku local, kulit.

Phone : 082125988152/

087770068289

Facebook : @ zolaleather

Instagram : @zola_leather

Zola leather memiliki ciri khas 'kulit', Jenis jenis kulit yang pakai : krom (kulit sapi) pull up (pull up cracking), (pull up glossy), vintage, karakter halus doff, a) Wawancara

wawancara dengan narasumber yaitu pemilik UKM Zola leather, staf penjualan dan produksi UKM tersebut

\section{b) Observasi}

Observasi dilakukan untuk mencari solusi dalam merancang Satchel bag yang dapat digunakan oleh konsumen Zola Leather.

Data sekunder berupa data literatur yang diperoleh dari buku, artikel, jurnal, dan laporan penelitian terdahulu.

\section{Teknik Analisis Data}

Teknik Analisis data yang dipakai ialah kualitatif, kualitatif merupakan upaya yang dilakukan dengan jalan bekerja dengan data. Beberapa Teknik analisis data yang digunakan agar mendapatkan rekomendasi yang dapat dikembangkan menjadi konsep desain, yaitu analisis SWOT dan analisis BCG. Hasilnya menjadi rekomendasi untuk membangun konsep desain

Natural milk, tekture tebal, lembut dan lentur, simone, kulit sapi Italian leather. Harga produk pada rentang dari Rp. 75.000 - Rp. 1.800.000. Perminggu 50-100 pes. Material kulit, canvas kombinasi kulit, batik, tenun, nylon.

Visi : ingin menjadi penghasil karya tas terlengkap.

Misi : 1. Membuka gerai setiap kota

2. Memperkuat online marketing

3. Memperbanyak karyawan

\section{b. Manajemen Produksi}

Karyawan : 5 Admin, 4 packing, 2 office girl, 9 produksi.

Tempat Produksi : Ciampea, Bogor. 
Teknik Produksi : Jahit, Teknik Coloring, Teknik Print

Jenis produksi : Tas, dompet, aksesoris

\section{c. Manajemen Pemasaran}

UKM Zola leather menerapkan beberapa dalam meningkatkan penjualannya, yaitu :

\section{Reseller}

Menjual kembali barang dengan biaya Awal Rp. 500.000 mendapat Pouch kulit roomy + brosur katalog foto produk Zola Leather. 1 pcs produk memperoleh potongan sebesaqr $15 \%$ Wajib menjual 1 produk dalam 1 bulan.

\section{Social Media}

Media sosial yang sering digunakan untuk pemasaran atau promosi di antaranya Fanpage Facebook, Instagram. Melalui media ini perusahaan bisa melakukan promosi yang terstruktur dan tepat sasaran.

\section{Pre Order}

Melakukan Dp 50\% dan sisanya jika baranng siap kirim, waktu pengerjaan 2-4 minggu.

\section{Penjualan lewat marketplace}

Selain penjualan konvensional, promosi di media sosial, Zola Leather memasarkan produknya di marketplace Shoppee dan Lazada.

\section{d. Analisis SWOT}

Tabel 1. STRATEGI S-W-O-T Zola Leather. STRATEGI - SO ZOLA LEATHER

\begin{tabular}{|l|l|}
\hline \multirow{2}{*}{$\begin{array}{l}\text { 5. selalu } \\
\text { meningkatkan }\end{array}$} & (S2) Material 100\% local premium. \\
\cline { 2 - 2 } $\begin{array}{l}\text { kualitas dan } \\
\text { creativitas yang }\end{array}$ & (S3) Karyawan yang creative \\
\cline { 2 - 2 } $\begin{array}{l}\text { baik. (S2, S3, S6, } \\
\text { O1) }\end{array}$ & $\begin{array}{l}\text { karena dilingkungan masyarakat dan } \\
\text { remaja yang mayoritas pelajar dan }\end{array}$ \\
\cline { 2 - 2 } & mhasiswa yang memakai tas. \\
\hline
\end{tabular}

STRATEGI - ST ZOLA LEATHER

\begin{tabular}{|l|l|}
\hline 6. meningkatkan & (S1) Pemasaran yang luas. \\
\cline { 2 - 2 } pemasaran serta ide & (S4) Showroom yang strategis. \\
yang menarik agar & \\
\cline { 2 - 2 } dikenal luas oleh & (S5) Selalu mengikuti Tren. \\
masyakat. (S1, S4, & \\
S5, T3) &
\end{tabular}

\section{STRATEGI - WO ZOLA LEATHER}

\begin{tabular}{|l|l|}
\hline $\begin{array}{l}\text { 7. membuat inovasi agar } \\
\text { menjadi daya Tarik }\end{array}$ & (W1) Desain yang seadanya. \\
masyarakat. (W1, O1, O3) & $\begin{array}{l}\text { (O1) Brand local kulit } \\
\text { sintesis. }\end{array}$ \\
\cline { 2 - 2 } & $\begin{array}{l}\text { (O3) Daya beli masyarakat } \\
\text { yang cukup tinggi. }\end{array}$ \\
\hline
\end{tabular}

STRATEGI - WT ZOLA LEATHER

\begin{tabular}{|l|l|}
\hline 8. membuat kerja sama & (W2) Harga terlalu mahal. \\
dengan orang lain sehingga & \\
\cline { 2 - 2 } $\begin{array}{l}\text { membuat perusahaan } \\
\text { berkembang dan selalu } \\
\text { membuat discount }\end{array}$ & (W3) Tidak memiliki website. \\
menarik. (W2, W3, W4, & (W4) Sumberdaya yang \\
T1, T2) & minim. \\
\cline { 2 - 2 } & (T1) Banyak produk yang \\
& (T2) Harga bahan baku yang \\
& cepat berubah. \\
\hline
\end{tabular}

\section{e. Analisis BCG}

Zola Leather memiliki 5 produk yang terdiri dari :

Tabel 2. Harga jual produk Zola Leather.

\begin{tabular}{|l|l|}
\hline PRODUK & HARGA JUAL \\
\hline Sling Bag & Rp. 550.000 \\
\hline Dompet & Rp. 350.000 \\
\hline Card Holder & Rp. 350.000 \\
\hline Gantungan Kunci & Rp. 75.000 \\
\hline Pouch & Rp. 250.000 \\
\hline
\end{tabular}

Data yang digunakan untuk analisis BCG dalam UMKM zola leather yang telah terpilih adalah volume penjualan zola leather dan total volume penjualan pesaing, tahap selanjutnya untuk menentukan letak produk pada kuadran BCG dengan menghitung tingkat pertumbuhan pasar dan pangsa relative. 
Data Penjualan Tahun 2018 UMKM

\section{Zola Leather}

Tabel 3. Data penjualan 2018 UMKM Zola Leather

\begin{tabular}{|l|l|l|}
\hline & $\begin{array}{c}\text { Penjualan } \\
\text { Januari s/d } \\
\text { Desember 2018 }\end{array}$ & $\begin{array}{c}\text { Market } \\
\text { Share }\end{array}$ \\
\hline Sling Bag & Rp. 750.000.000 & $25.00 \%$ \\
\hline Dompet & Rp. 685.000.000 & $22.83 \%$ \\
\hline Card Holder & Rp. 565.000.000 & $18.83 \%$ \\
\hline Gantungan Kunci & Rp. 595.500.000 & $19.83 \%$ \\
\hline Pouch & RP. 404.500.000 & $13.48 \%$ \\
\hline
\end{tabular}

Data Penjualan Tahun 2019 UMKM

\section{Zola Leather}

Tabel 4. Data penjualan 2019 UMKM Zola Leather

\begin{tabular}{|l|l|l|}
\hline & $\begin{array}{l}\text { Penjualan Januari } \\
\text { s/d Desember 2019 }\end{array}$ & $\begin{array}{l}\text { Market } \\
\text { Share }\end{array}$ \\
\hline Sling Bag & Rp. 878.310.000 & $25.09 \%$ \\
\hline Dompet & Rp. 797.810.000 & $22.79 \%$ \\
\hline Card Holder & Rp. 590.800.000 & $16.88 \%$ \\
\hline Gantungan Kunci & Rp. 637.500.000 & $18.21 \%$ \\
\hline Pouch & Rp. 595.580.000 & $17.01 \%$ \\
\hline
\end{tabular}

f. Perhitungan Tingkatan Pertumbuhan Pasar (TPP)

$$
T P P=\frac{\mathrm{VP} \mathrm{N}-\mathrm{VP} \mathrm{N}-1}{\mathrm{VP} \mathrm{N}-1} \times 100
$$

TPP = Tingkat Pertumbuhan Pasar

VPN =Volume Penjualan Perusahaan tahun Terakhir

VP N =Volume Penjualan Perusahaan Tahun Sebelumnya

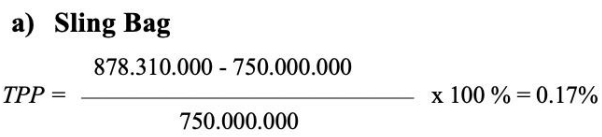

\section{b) Dompet}

$T P P=\frac{797.810 .000-685.000 .000}{685.000 .000} \times 100 \%=0.16 \%$

c) Card Holder

$T P P=\frac{590.800 .000-565.000 .000}{565.000 .000} \times 100 \%=0.45 \%$

d) Gantungan Kunci

$T P P=\frac{595.580 .000-404.500 .000}{404.500 .000} \times 100 \%=0.47 \%$

e) Pouch

$637.500 .000-595.500 .000$

$T P P=\frac{595.500 .000}{100} \%=0.70 \%$

Hasil perhitungan tingkat pertumbuhan didapatkan penjualan Sling Bag 0.17\%, Dompet 0.16\%, Card Holder $0.45 \%$, Gantungan Kunci $0.70 \%$. Dalam matriks BCG Zola Leather memiliki tingkat perumbuhan pasar yang tinggi, terlihat dari kenaikan penjualan dari tahun 2018-2019.

\section{g. Matriks BCG}

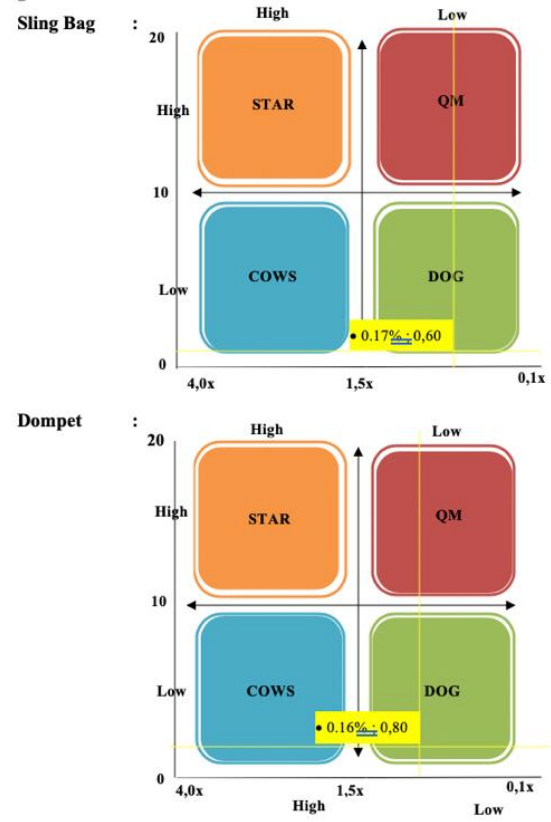




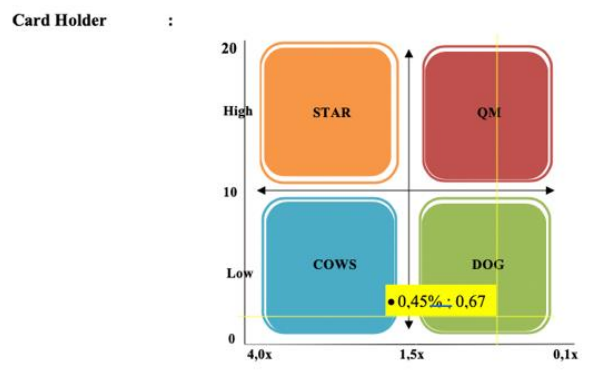

Gantungan Kunci

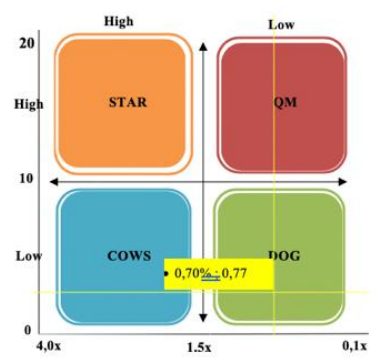

h. Perhitungan Pangsa Pasar Relatif $P P R=$ VPN

$$
\text { VPPN }
$$

PPR = Pangsa Pasar Relative

VPN = Volume Penjualan Tahun

Terakhir

VPP N = Volume Penjualan Pesaing Tahun

Terakhir

a) Sling Bag

$$
P P R=\frac{878.310 .000}{1.455 .000 .000}=0,60
$$

b) Dompet

$$
P P R=\frac{797.810 .000}{985.500 .000}=0,80
$$

c) Card Holder

$$
P P R=\frac{590.800 .000}{879.500 .000}=0,67
$$

d) Gantungan Kunci

$$
P P R=\frac{637.500 .000}{825.000 .000}=0,77
$$

e) Pouch

$$
P P R=\frac{595.580 .000}{655.000 .000}=0,90
$$

\section{Konsep Desain}

Konsep desain Satchel Bag ini adalah tas yang memiliki 2 fungsi sekaligus yaitu dapat digunakan untuk hand bag dan di sling bag. Tali (strap) untuk sling bag terbuat dari dapat diatur panjang - pendek nya.

Satchel bag ini memiliki fitur fungsi lainnya dengan memiliki 2 slot bagian dalam tas, dan beberapa kantong di bagian dalam lainya, sehingga walaupun ukuran nya medium, tas ini mempunyai daya tamping banyak.

Tampilan produk ini memiliki warna yang anggun, desain nya sederhana sehingga dapat digunakan ke acara formal ataupun non formal. Detail produk dari terdapat beberapa kantong dalam, lipatan lipatan. Teknik jahitan luar dengan benar yang besar membentuk detail jahitan terlihat tegas.

\section{Pengembangan Desain}

\section{a) Sketsa Desain Platform}

Selanjutnya konsep desain dikembangkan ke dalam desain bentuk dasar yang dapat dikembangkan ke dalam berbagai alternatif desain (desain platform).

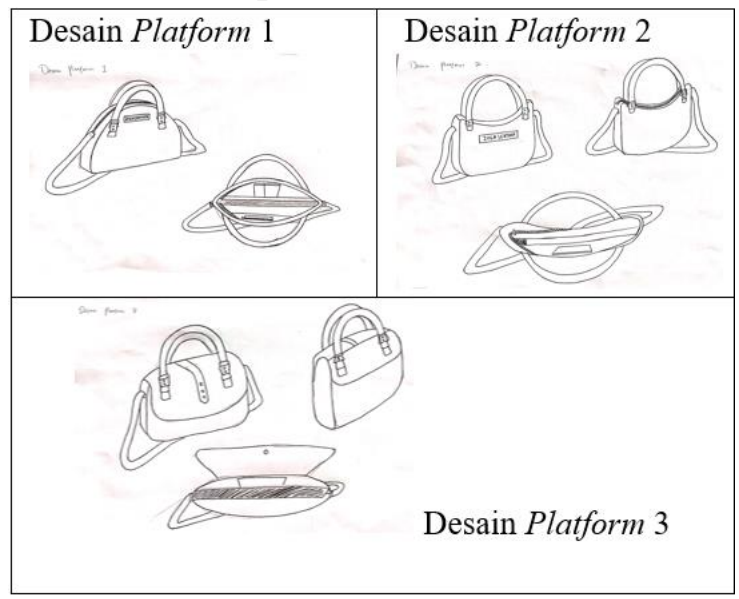

Gambar 1. Skesta Desain Platform

\section{b) Refining}

Pada tahapan refining ini desain terpilih diperbaiki desain dan ditambahkan bagian fitur-fitur nya sampai terlihat perbedaan nya antar satu sama lain. 


\section{a. Desain Platform 1}

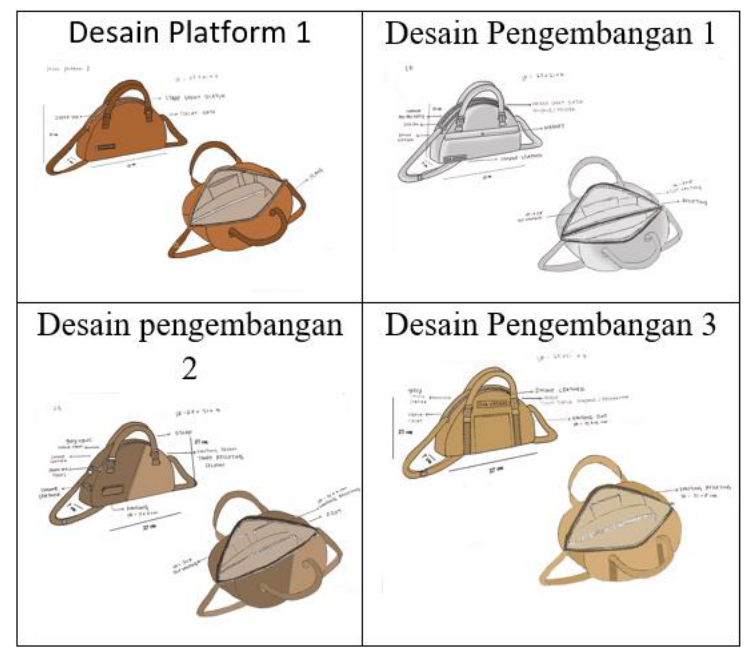

Gambar 2. Sketsa refining Platform 1

\section{b. Desain Platform 2}

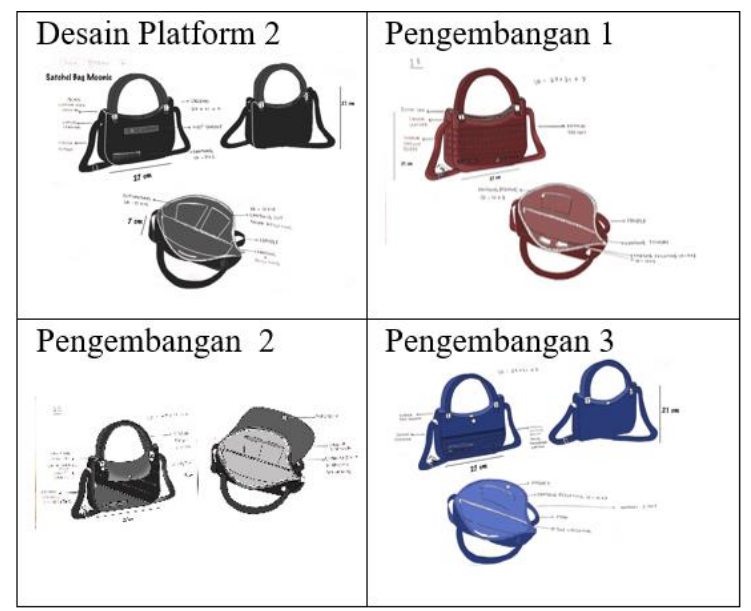

Gambar 3. Sketsa refining Platform 2

\section{c. Desain Platform 3}

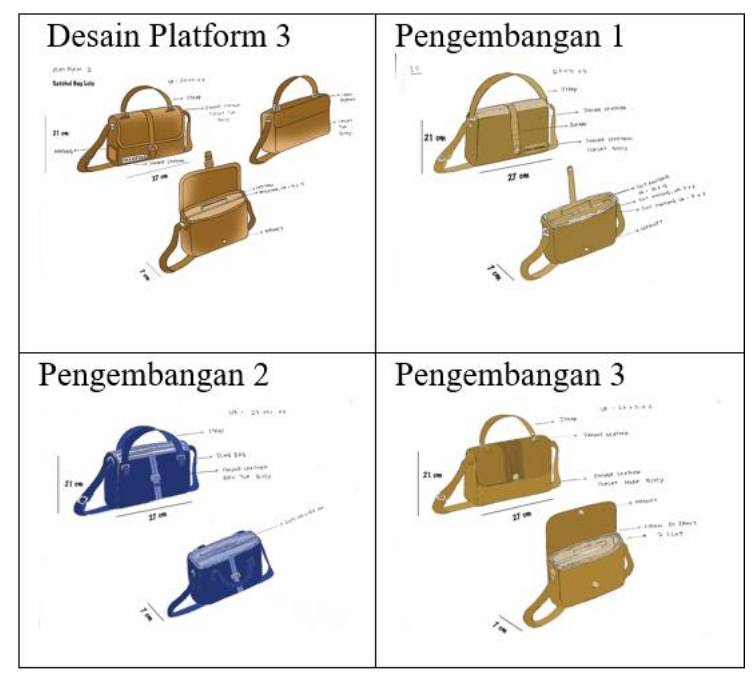

Gambar 4. Sketsa refining Platform 3

\section{d) Pemilihan Desain}

Pada tahap pemilihan Desain dilakukan langsung oleh pemilik Zola Leather, Ibu Mira. Desain Platform 2 adalah desain terpilih, namun dengan beberapa revisi. Revisi bertujuan agar tampilan tas terlihat simple. Karena untuk saat ini Zola Leather menjaga ciri khas nya sebagai tas yang simple dan anggun.

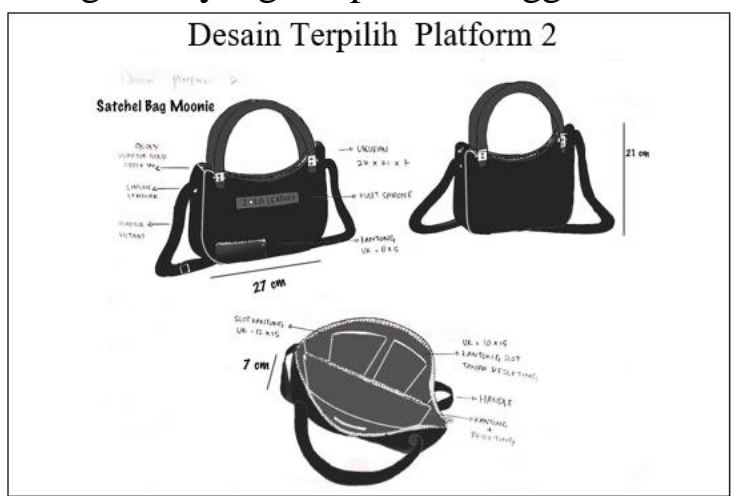

Gambar 5. Desain Terpilih

\section{e) Desain Akhir}

Pada desain terpilih kemudian direvisi, hingga menjadi desain yang benar - benar siap diproduksi. Revisi yang yang diajukan adalah memperkuat kesan simpel, memiliki warna hitam, merah marun dan $\tan$.

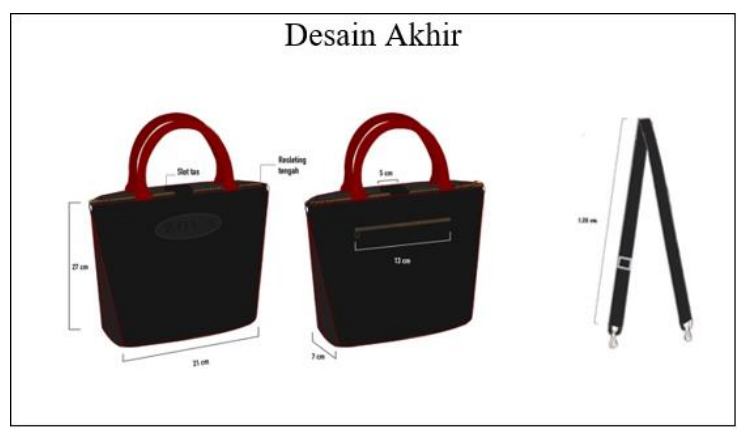

Gambar 6. Desain Akhir 


\section{KESIMPULAN DAN SARAN}

\section{Kesimpulan}

Proses perancangan satchel bag ini dilakukan proses penelitian awal berupa survey,wawancara, observasi, dan studi Pustaka. Selanjutnya data yang didapatkan dianalisis dengan teknik analisis SWOT, BCG.

Desain satchel bag desain ini dibuat ukuran yang lebih kecil dari ukuran awal nya karena dengan meminimalisir ukuran akan mengurangi material kulit yang dibutuhkan nya.Tujuannya mendapatkan produk dengan harga pokok jual yang menengah sehingga dapat bersaing dengan kompetitornya.

\section{DAFTAR PUSTAKA}

American Heritage Dictionary. 2000. The American Heritage Dictionary of English Language. Boston: Houghton Mifflin Harcourt.

Collins English Dictionary (2009) 'ethos', in Collins English Dictionary: Complete and unabridged, 10th edn. London: HarperCollins

J.Moleong, Lexy. (2014). Metode Penelitian Kualitatif, Edisi Revisi. PT Remaja Rosdakarya, Bandung.

Moleong, Lexy J. (2007) Metodologi Penelitian Kualitatif, Penerbit PT Remaja Rosdakarya Offset, Bandung
Desain terpilih dari rancangan ini memiliki hand bag dengan strap yang dapat di atur sesuai kebutuhan. Tetapi setelah di review oleh pemilik UMKM Zola Leather, terjadi revisi. desain akhir mengalami perubahan dibagian handle dan bentuk nya lebih simple. Hal ini bertujuan untuk menjaga ciri khas dari produk Zola Leather.

\section{Saran}

Pada penelitian selanjutnya diharapkan ada fase pengukuran performa fungsi produk. Hal ini untuk memastikan fitur yang ditawarkan dapat benar - benar berfungsi dan menjawab kebutuhan pengguna.

Rangkuti, Freddy. 2001. Analisis SWOT Teknik Membelah Kasus Bisnis. PT. Gramedia Pustaka Utama. Jakarta.

Robert G. Dyson (1990). Strategic development and SWOT analysis at the University of Warwick. In Elsevier - European Journal of Operational Research

Salim Peter. (2000). Salim's Ninth Collegiate English-Indonesian Dictionary. Jakarta: Modern English Press.

Sugiyono. (2016). Metode Penelitian Kuantitatif, Kualitatif dan R\&D. Bandung: PT Alfabet. 